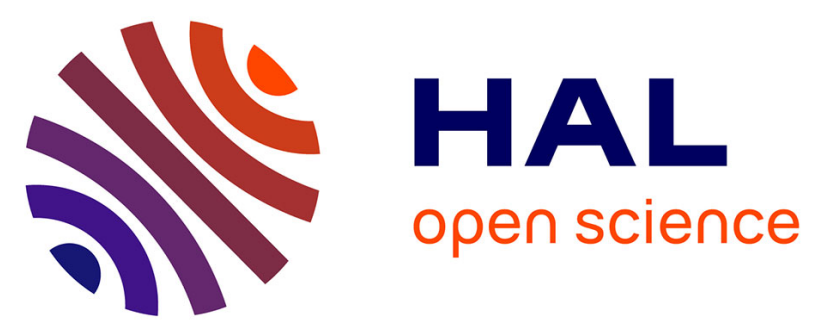

\title{
Consequences of a multi-generation exposure to uranium on Caenorhabditis elegans life parameters and sensitivity.
}

Benoit Goussen, Florian Parisot, Rémy Beaudouin, Morgan Dutilleul, Adeline Buisset-Goussen, Alexandre R.R. Pery, Jean-Marc Bonzom

\section{To cite this version:}

Benoit Goussen, Florian Parisot, Rémy Beaudouin, Morgan Dutilleul, Adeline Buisset-Goussen, et al.. Consequences of a multi-generation exposure to uranium on Caenorhabditis elegans life parameters and sensitivity.. Ecotoxicology, 2013, 22 (5), pp.869-878. 10.1007/s10646-013-1078-5 . irsn-00838826

\section{HAL Id: irsn-00838826}

https://hal-irsn.archives-ouvertes.fr/irsn-00838826

Submitted on 1 Jun 2014

HAL is a multi-disciplinary open access archive for the deposit and dissemination of scientific research documents, whether they are published or not. The documents may come from teaching and research institutions in France or abroad, or from public or private research centers.
L'archive ouverte pluridisciplinaire HAL, est destinée au dépôt et à la diffusion de documents scientifiques de niveau recherche, publiés ou non, émanant des établissements d'enseignement et de recherche français ou étrangers, des laboratoires publics ou privés. 


\title{
Consequences of a multi-generation exposure to uranium on Caenorhabditis elegans life parameters and sensitivity
}

\author{
Benoit Goussen* ${ }^{1,2}$, Florian Parisot ${ }^{2}$, Rémy Beaudouin ${ }^{1}$, Morgan Dutilleul $^{2}$, Adeline \\ Buisset-Goussen ${ }^{2}$, Alexandre R.R. PÉRY ${ }^{1}$, and Jean-Marc Bonzom ${ }^{2}$ \\ ${ }^{1}$ Unité Modèles pour l'Ecotoxicologie et la Toxicologie (METO), Institut National de l'Environnement Industriel et des Risques \\ (INERIS), BP2, F-60550 Verneuil en Halatte, France \\ 2 Institut de Radioprotection et de Sûreté Nucléaire (IRSN), PRP-ENV, SERIS, Laboratoire d'ECOtoxicologie des radionucléides \\ (LECO), Cadarache, France
}

Final version: Goussen B., Parisot F., Beaudouin R., Dutilleul M., Buisset-Goussen A., Péry A.R.R., Bonzom J.-M. (2013) Consequences of a multigeneration exposure to uranium on Caenorhabditis elegans life parameters and sensitivity. Ecotoxicology. pp.1-10. DOI 10.1007/s10646-013-1078-5. The final publication is available at link.springer.com

\section{Abstract}

The assessment of toxic effects at biologically and ecologically relevant scales is an important challenge in ecosystem protection. Indeed, stressors may impact populations at much longer term than the usual timescale of toxicity tests. It is therefore important to study the evolutionary response of a population under chronic stress. We performed a 16-generation study to assess the evolution of two populations of the ubiquitous nematode Caenorhabditis elegans in control conditions or exposed to $1.1 \mathrm{mM}$ of uranium. Several generations were selected to assess growth, reproduction, survival, and dose-responses relationships, through exposure to a range of concentrations (from 0 to $1.2 \mathrm{mM}$ U) with all endpoints measured daily. Our experiment showed an adaptation of individuals to experimental conditions (increase of maximal length and decrease of fecundity) for both populations. We also observed an increase of adverse effects (reduction of growth and fertility) as a function of uranium concentration. We pointed out the emergence of population differentiation for reproduction traits. In contrast, no differentiation was observed on growth traits. Our results confirm the importance of assessing environmental risk related to pollutant through multi-generational studies.

Keywords: Caenorhabditis elegans Multigenerations experiment Evolutionary ecotoxicology Uranium

*Corresponding author. Email: benoit.goussen@gmail.com

\section{Introduction}

Ecological risk assessment relies directly on the ability to assess risk at biologically and ecologically relevant scales. When targeting ecosystems protection, the relevant ecological timescales would be at least four generations of exposed populations in order to neglect acclimation effects (Gagliano and McCormick, 2007; Mousseau and Fox, 1998; Muyssen and Janssen, 2004; Räsänen and Kruuk, 2007; Scheiner, 1993). However, until recent years and the emergence of the concept of evolutionary ecotoxicology, most of the ecotoxicological studies do not even cover one full generation, as only partial life cycle tests are more common that full life cycle ones. Consequently there are only a few datasets and models that account for adaptive processes which may appear in a population submitted to stressful conditions for several generations. However, if chronically applied, a stressful condition may constitute a selective pressure in natural populations (Bickham, 2011; Coutellec et al., 2011), leading to evolutionary adaptive processes (Coutellec and Barata, 2011). As also noted by Dutilleul et al. (2013), modifications in the environment such as the apparition of pollutants can lead a population to three types of responses. Whereas the first two, i.e. within-individual phenotypic plasticity (Scheiner, 1993) and cross-generation phenotypic plasticity (Räsänen and Kruuk, 2007) can be detected during the first two generations of the experiment, the third type, local adaptation (Hendry and Gonzalez, 2008) can only be detected by studying more generations (Hoffmann and Merilä, 1999).

The free living nematode Caenorhabditis elegans (Maupas, 1900) is a relevant biological model for evolutionary ecotoxicology assessments because of its short life span, short life cycle, small size, high fecundity and ease to culture in laboratory conditions (Brenner, 1974; Byerly et al., 1976). This nematode is therefore widely used in the assessment of pollutant effects (Boyd et al., 2003; Harada et al., 2007; Shen et al., 2009; Sochová et al., 2007; Swain et al., 2004, 2010) and 
of evolutionary responses (Lopes et al., 2008; Morran et al., 2009a,b). C. elegans reproduces by androdioecy (hermaphrodites can self-fertilize, the presence of male is optional) and according to Morran et al. (2009a), facultative outcrossing may facilitate adaptation to stress.

Our study focused on uranium as pollutant of interest. It is a radioactive heavy metal naturally found in the environment. Uranium is both a chemical and radiological toxicant. Nevertheless, its chemical toxicity is considered to be dominant over its radiotoxicity (Sheppard et al., 2005; Zeman et al., 2008). The soil concentration of natural uranium is around $0.008 \mathrm{mM}$ $\left(2 \mathrm{mg} \mathrm{kg}{ }^{-1}\right)$ but it can reach up to 0.2 to $4.2 \mathrm{mM} \mathrm{U}$ (50 to $1000 \mathrm{mg} \mathrm{kg}^{-1}$ ) in contaminated areas (Ribera et al., 1996; UNSCEAR, 2000).

In the present study, in order to better evaluate the effects of a long-term exposure to uranium on a nematode population, we compared the evolution of growth, reproduction, survival, and dose-response relationships for uranium in two populations of $C$. elegans (a control population and a population exposed to a sublethal concentration of uranium) exposed over 16 generations. The aim of this study is to better evaluate the modification of the response to uranium throughout the generations. Preliminary studies showed a decrease of fecundity by over $60 \%$ for C. elegans individuals exposed to $1.1 \mathrm{mM} \mathrm{U}$ (data not shown). Due to this strong selection pressure, only $40 \%$ of the individuals are selected for the next generation. This would induce a selection of around $2.5 \%$ of the individuals at the fourth generation. Regarding this background, we expected a rapid evolution of the exposed population in less than four generations followed by stabilization.

\section{Materials and Methods}

\subsection{Test organism}

Caenorhabditis elegans is an ubiquitous free nematode. It measures $250 \mathrm{\mu m}$ long at hatching and up to $1.4 \mathrm{~mm}$ at adult stage. This nematode is a powerful model in evolutionary ecotoxicology experiments because of its short life cycle ( $C$. elegans breeds in three days at $\left.20^{\circ} \mathrm{C}\right)$, its short life span $\left(21\right.$ days at $\left.20^{\circ} \mathrm{C}\right)$, and its high fecundity (Byerly et al., 1976).

The $C$. elegans population $E E V-\mathrm{A}_{0}$ used in this study was created by Teotónio et al. (2012) from a mixture of 16 wild isolates. These authors derived their androdioecious population through a funnel cross strategy. Briefly, two-isolate hybrids were obtained by crossing, in a pair-wise fashion, each of the wild isolate. Then four-isolate hybrids were obtained by intercrossing in a pair-wise fashion the two-isolate hybrids. Hybridizations continued until the 16 -isolate hybrids were created. The population was then maintained over 140 generations. They did not observe significant loss of genetic diversity after recombination-selection equilibrium was mostly reached. As the EEV-A $\mathrm{A}_{0}$ population is genetically highly diverse, adaptation processes may be expected to occur. Indeed, such kind of adaptive response can only be observed when genetic variation is sufficient in the studied population. This population is composed of around $30 \%$ of males.

In the present study, two populations were derived from this strain. Nematode populations were maintained at $20^{\circ} \mathrm{C}, 80 \% \mathrm{RH}$ in $9 \mathrm{~cm}$ Petri dishes filled with nematode growth medium (NGM) seeded with Escherichia coli strain OP50 (Brenner, 1974; Stiernagle, 2006).

\subsection{Multigeneration exposure}

Two populations were derived from the EEV-A $\mathrm{A}_{0}$ population. Nematodes were washed off the Petri-dishes of the EEV-A $\mathrm{A}_{0}$ population with a M9-modified buffer (use of HEPES buffer instead of potassium phosphate buffer). The nematodes we picked up were then pooled in a $15 \mathrm{~mL}$ falcon tube and the number of individuals in the tube was estimated based on three sample drops of $5 \mu \mathrm{L}$ (Teotónio et al., 2012). Then volumes corresponding to 500 individuals were transferred to three new $9 \mathrm{~cm}$ Petri dishes for each population. Two populations were followed over 16 generations on $9 \mathrm{~cm}$ Petri dishes. One population was the control population (thereafter called MGC), the other was exposed to a nominal concentration of $1.1 \mathrm{mM}$ of uranium (thereafter called MGU). The Petri dishes were filled with NGM which had to be modified compared to the experimental conditions by Teotónio et al. (2012). We replaced $25 \mathrm{mM}$ of potassium phosphate buffer $(\mathrm{pH} 6)$ by $25 \mathrm{mM}$ of HEPES buffer (pH 5.5, Sigma-Aldrich, France). Indeed, in presence of inorganic phosphate, uranium bioavailability and toxicity decrease due to the formation of an uranyl phosphate complex (Misson et al., 2009; Mkandawire et al., 2007). The uranium stock solution was obtained by a dilution of uranyl nitrate $\left(\mathrm{UO}_{2}\left(\mathrm{NO}_{3}\right)_{2}, 6 \mathrm{H}_{2} \mathrm{O}\right.$, Sigma-Aldrich, France). Uranium solution was added to the modified NGM just before flowing the plates. $100 \mu \mathrm{L}$ of NGM samples were collected for each treatment and stored at $4^{\circ} \mathrm{C}$. The samples were digested with a combination of $1 \mathrm{~mL} \mathrm{HNO}_{3}$ and $1 \mathrm{~mL} \mathrm{H}_{2} \mathrm{O}_{2}$ at $90^{\circ} \mathrm{C}$ prior to measurement with ICP-AES (Optima 4300 DV, Perkin-Elmer, USA; detection limit $0.04 \mu \mathrm{M})$.

E. coli OP50 cultures were grown overnight in LBroth rich medium at $37^{\circ} \mathrm{C}$. Then cultures $\left(\mathrm{OD}_{600}\right.$ $=3$ ) were washed twice with a $5 \mathrm{~g} \mathrm{~L}^{-1} \mathrm{NaCl}$ solution in order to remove LB medium, since it contains phosphate. Petri dishes were seeded with $1 \mathrm{~mL}$ of a 20:1 mixture and left overnight to allow the bacterial culture to dry. Petri dishes were then exposed to UV doses (Bio-Link Crosslinker, $\lambda=254 \mathrm{~nm}$; intensity = 200 uwatt $\mathrm{m}^{-2}$ ) for 15 minutes to stop bacterial growth and to avoid uncontrolled heterogeneity in food availability between populations. Indeed, Boyd et al. (2003) showed that $C$. elegans responses to heavy metal toxicant can be function of the food availability. The nematodes were assumed to be fed ad libitum.

Every three days, nematodes were washed off the 
Petri dishes with a M9-modified solution. Nematodes picked up from all Petri dishes of one population were pooled in a $15 \mathrm{~mL}$ falcon tube in order to avoid increasing the number of groups to be followed which permitted to match our technical facilities. The number of individuals in a tube was estimated based on three sample drops of $5 \mu \mathrm{L}$ (Teotónio et al., 2012). Then the volume corresponding to 500 individuals was transferred to three new Petri dishes.

\subsection{Toxicity test}

At generations $0,2,3,6,12$, and 16, individuals from both populations were exposed to a range of 7 concentrations of uranium: 0 (control), $0.1,0.3,0.5,0.9$, 1.1, $1.2 \mathrm{mM} \mathrm{U}$. For this purpose 12-well tissue-plates were used. Contamination protocol was the same as for $9 \mathrm{~cm}$ Petri dishes. Around 60 gravid hermaphrodites were randomly picked up from respectively MGC and MGU population plates. These individuals were placed on two set of new plates (one set by population) and allowed to lay eggs for 90 minutes. Eggs were then deposited in the 12-well tissue-plates. One egg was deposited per well and at least 12 wells were used for each concentration and each population. Survival, growth, and egg laying were monitored individually for 8 days. Survival was measured by stimulating each worm with a platinum transfer pick. The nematode was scored as dead if no head or body movement was triggered by three repeated stimulations (Sutphin and Kaeberlein, 2009; Swain et al., 2004). Nematodes were photographed daily using a stereomicroscope (ZEISS SteREO Discovery V20, x240 and x160 magnification respectively for juveniles and adults) coupled with a computer-connected camera (Nikon D5000). Body length was measured using ImageJ software (Rasband, 2012) and a micrometer scale measure. Egg laying was recorded by visual scoring. The few worms that were lost by crawling off the plate or desiccating on the sides of the plates were removed from data. Similarly, individuals that could not be sexed were discarded. As all individuals exposed at a nominal concentration of $1.1 \mathrm{mM} \mathrm{U}$ for the generation 0 did not grow enough to be sexed and since we did not observed any sexual differences for individuals of this length, we decided to include them as both male and hermaphrodite in the analysis. The experimental design is presented in Figure 1.

\subsection{Data analysis}

Growth data were modelled thanks to a Gompertz model:

$$
L=L_{i n f} \times \exp ^{\ln \left(\frac{L_{0}}{L_{i n f}}\right) \times \exp ^{-a t}}
$$

where $L_{\text {inf }}$ is the maximal length, $L_{0}$ is the hatching length and $a$ is a constant related to growth rate. Cumulated egg laying at 126 hours post hatching was

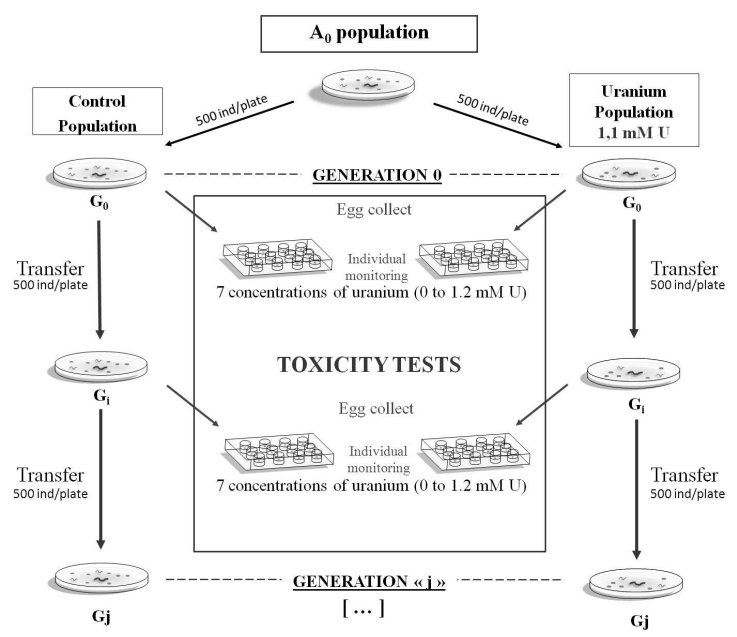

Figure 1: Schematic overview of the experimental design. The $A_{0}$ population is the original population. Uranium population (MGU) was exposed to $1.1 \mathrm{mM} \mathrm{U}$ during all the experiment. Uranium population (MGU) and Control population (MGC) were transferred in new dishes every three days. For selected generations, eggs were collected in MGC and MGU and were respectively submitted to toxicity tests

assumed to be total egg laying (called fecundity thereafter) as we observed no egg laying after this period in all preliminary experimentations in the laboratory.

Effects of uranium on $L_{i n f}, L_{0}, a$ and fecundity were tested through an analysis of variance with Dunnett's and Tukey's all-pair comparison tests as post hoc comparison tests. Model adjustment and statistical analysis were performed with the statistical computing software R 2.15 (R Core Team, 2012).

Dose-responses and half maximal effective concentration $\left(\mathrm{EC}_{50}\right)$ were calculated using a logistic model fitted with least squares optimization method using the "drc" R-package (Ritz and Streibig, 2005). Results are considered as statistically significant if the $p$-value is less than 0.05 .

\section{Results}

\subsection{Actual exposure concentrations}

Initial uranium concentrations in the NGM obtained by ICP-AES were close to nominal concentration. We observed less than $10 \%$ of differences in $82 \%$ of the cases and less than $15 \%$ in $94.6 \%$. The most important difference was observed on the toxicity test at $1.1 \mathrm{mM} \mathrm{U}$ for the generation 0 (measured at $1.48 \mathrm{mM} \mathrm{U}$ ). In order to facilitate the reading of this study, nominal concentrations are used in figures and in the text.

\subsection{Model Fitting}

The Gompertz model we used (Eq. (1)) provided a relevant fit of the growth data we obtained either for male or hermaphrodite individuals. Indeed, the $\mathrm{R}^{2}$ value was greater than 0.8 in $81 \%$ of the cases ( $>0.9$ in $61 \%$ ) 

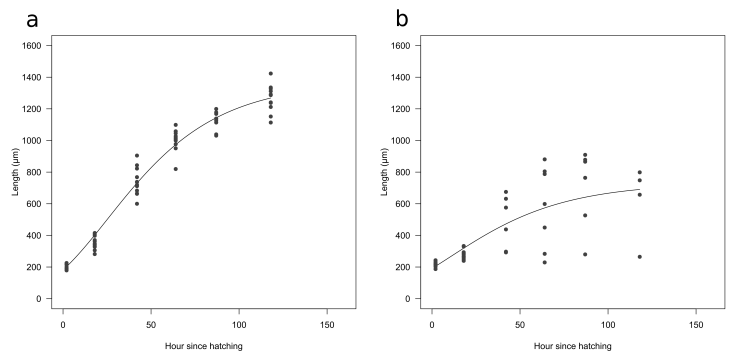

Figure 2: Two examples (a and b) of C. elegans length $(\mu \mathrm{m})$ in relation to age (hour since hatching). Observed data are represented by points, the Gompertz model (Eq. (1)) is represented by the regression line. "a" corresponds to data obtained with individuals exposed to control conditions with the following estimated parameters values: maximal length $\left(L_{i n f}\right)=1370 \mu \mathrm{m}$, hatching length $\left(L_{0}\right)=$ $182 \mu \mathrm{m}$, and growth rate $(a)=0.028$. "b" corresponds to data obtained with individuals exposed to $1.2 \mathrm{mM} \mathrm{U}$ with the following estimated parameters values maximal length $\left(L_{i n f}\right)=731 \mu \mathrm{m}$, hatching length $\left(L_{0}\right)=191 \mu \mathrm{m}$, and growth rate $(a)=0.027$

for males and greater than 0.8 in $77 \%$ of the cases $(>$ 0.9 in $56 \%$ ) for hermaphrodites. As illustrated by Figure 2 , all the cases with a $\mathrm{R}^{2}$ below 0.8 were caused by scattered data (Fig.2b). The parameters estimates were consistent with physiological data and literature (Altun and Hall, 2009; Araiz et al., 2008; Byerly et al., 1976).

\subsection{MGC life cycle parameters}

For maximal length, male maximal length was constant throughout the generations (Anova $\mathrm{F}_{5,30}=$ $1.001, p=0.434$, Fig. 3A). In contrast, hermaphrodite individuals showed a significant increase until generation six and remained constant afterwards (Anova $\mathrm{F}_{5,30}=3.521, p=0.013$, Fig. 3B). The hatching length oscillated throughout the generations in males and hermaphrodites (Anova Table 1, Fig. 4). Fecundity showed a significant decrease until generation three and remained constant afterwards (Anova $\mathrm{F}_{4,244}=34.56, p<0.001$, Fig. 5).

\subsection{MGU life cycle parameters}

The male hatching length $\left(L_{0}\right)$ was positively impacted by the uranium concentration (Anova Table 1) starting from $1.1 \mathrm{mM} \mathrm{U}$ (Dunnett post-hoc test $p<0.001$ ). The hermaphrodite hatching length $\left(L_{0}\right)$ was impacted by the uranium concentration for $1.1 \mathrm{mM} \mathrm{U}$ (Anova Table 1, Dunnett post-hoc test $p=0.02$ ). For all generations and both populations, there was a significant decrease of maximal length as a function of uranium exposure (Anova Table 1, Fig. 3, S1, and S2) starting from $1.1 \mathrm{mM} \mathrm{U}$ for both male and hermaphrodite individuals (Dunnett post-hoc test $p<0.001$ ). In the same way, fecundity was decreased as a function of uranium exposure concentration (Anova Table 1, Fig. 5, and S3) starting from $0.9 \mathrm{mM} \mathrm{U}$ (Dunnett post-hoc test $p<0.001$ ). Under conditions of constant exposure (i.e.
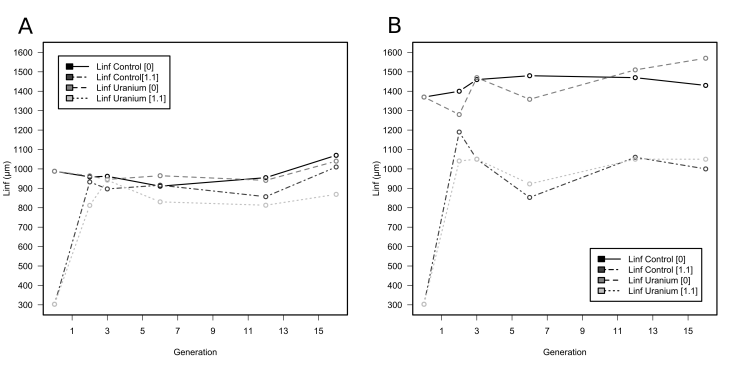

Figure 3: Male (A) and hermaphrodite (B) maximal length $L_{\text {inf }}(\mu \mathrm{m})$ for individuals issued from MGC (Control population) and MGU (Uranium population) exposed to control conditions or $1.1 \mathrm{mM} \mathrm{U}$, as a function of the generation. Each point represents the $L_{i n f}$ value of the model (Eq. (1)) fitted using all the replicates for each treatment. $L_{i n f}$ Control [0] represents maximal length for MGC exposed to control conditions, $L_{i n f}$ Control [1.1] represents maximal length for MGC exposed to $1.1 \mathrm{mM} \mathrm{U}, L_{i n f}$ Uranium [0] represents maximal length for MGU exposed to control conditions, and $L_{\text {inf }}$ Uranium [1.1] represents maximal length for MGU exposed to $1.1 \mathrm{mM} \mathrm{U}$.
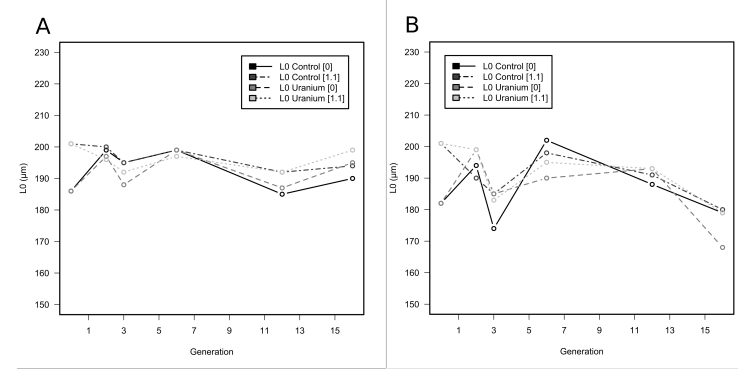

Figure 4: Male (A) and hermaphrodite (B) hatching length $L_{0}(\mu \mathrm{m})$ for individuals issued from MGC (Control population) and MGU (Uranium population) exposed to control conditions or $1.1 \mathrm{mM} \mathrm{U}$, as a function of the generation. Each point represents the $L_{0}$ value of the model (Eq. (1)) fitted using all the replicates for each treatment. $L_{0}$ Control [0] represents hatching length for MGC exposed to control conditions, $L_{0}$ Control [1.1] represents hatching length for MGC exposed to $1.1 \mathrm{mM} \mathrm{U}, L_{0}$ Uranium [0] represents hatching length for MGU exposed to control conditions, and $L_{0}$ Uranium [1.1] represents hatching length for MGU exposed to $1.1 \mathrm{mM} \mathrm{U}$. 
Table 1: Anova results for maximal length $\left(L_{i n f}\right)$, hatching length $\left(L_{0}\right)$, growth rate $(a)$, and fecundity with Population $(\mathrm{P})$, Generation $(\mathrm{G})$, and Concentration $(\mathrm{C})$ as factors. Main effects and first-order interaction are presented for both male and hermaphrodite for the estimated parameters $L_{i n f}, L_{0}$, and $a$. Main effects, first-order, and second-order interactions are presented for fecundity. d.f. represents the number of degrees of freedom, and $\mathrm{F}$ value represents the value of the Fisher statistic. ${ }^{*}=p$ value $<0.05,{ }^{* *}=p$ value $<0.01$, and ${ }^{* * *}=p$ value $<0.001$

\begin{tabular}{|c|c|c|c|c|c|}
\hline Observed traits & Variable & d.f. & $\mathrm{F}$ value & $p$ value & \\
\hline \multirow[t]{7}{*}{$L_{0}$ for male } & Population & 1 & 0.893 & 0.352 & \\
\hline & Generation & 5 & 54.240 & $<0.001$ & $* * *$ \\
\hline & Concentration & 6 & 11.490 & $<0.001$ & $* * *$ \\
\hline & $\mathrm{PxG}$ & 5 & 1.603 & 0.191 & \\
\hline & $\mathrm{PxC}$ & 6 & 2.229 & 0.069 & \\
\hline & $\mathrm{GxC}$ & 30 & 4.836 & $<0.001$ & $* * *$ \\
\hline & Residuals & 29 & & & \\
\hline \multirow[t]{7}{*}{$L_{0}$ for hermaphrodite } & Population & 1 & 0.722 & 0.403 & \\
\hline & Generation & 5 & 33.370 & $<0.001$ & $* * *$ \\
\hline & Concentration & 6 & 4.011 & 0.005 & $* *$ \\
\hline & $\mathrm{PxG}$ & 5 & 0.550 & 0.737 & \\
\hline & $\mathrm{PxC}$ & 6 & 0.275 & 0.944 & \\
\hline & $\mathrm{GxC}$ & 30 & 1.802 & 0.058 & \\
\hline & Residuals & 29 & & & \\
\hline \multirow[t]{7}{*}{$L_{i n f}$ for male } & Population & 1 & 0.087 & 0.770 & \\
\hline & Generation & 5 & 12.280 & $<0.001$ & $* * *$ \\
\hline & Concentration & 6 & 45.610 & $<0.001$ & $* * *$ \\
\hline & PxG & 5 & 0.432 & 0.822 & \\
\hline & $\mathrm{PxC}$ & 6 & 1.459 & 0.227 & \\
\hline & $\mathrm{GxC}$ & 30 & 10.430 & $<0.001$ & $* * *$ \\
\hline & Residuals & 29 & & & \\
\hline \multirow[t]{7}{*}{$L_{i n f}$ for hermaphrodite } & Population & 1 & 1.988 & 0.169 & \\
\hline & Generation & 5 & 32.650 & $<0.001$ & $* * *$ \\
\hline & Concentration & 6 & 159.400 & $<0.001$ & $* * *$ \\
\hline & $\mathrm{PxG}$ & 5 & 0.653 & 0.662 & \\
\hline & $\mathrm{PxC}$ & 6 & 0.213 & 0.970 & \\
\hline & $\mathrm{GxC}$ & 30 & 6.771 & $<0.001$ & $* * *$ \\
\hline & Residuals & 29 & & & \\
\hline \multirow[t]{7}{*}{$a$ for male } & Population & 1 & 1.556 & 0.222 & \\
\hline & Generation & 5 & 0.892 & 0.499 & \\
\hline & Concentration & 6 & 1.054 & 0.412 & \\
\hline & $\mathrm{PxG}$ & 5 & 1.045 & 0.411 & \\
\hline & $\mathrm{PxC}$ & 6 & 1.243 & 0.314 & \\
\hline & $\mathrm{GxC}$ & 30 & 0.883 & 0.632 & \\
\hline & Residuals & 29 & & & \\
\hline \multirow[t]{7}{*}{$a$ for hermaphrodite } & Population & 1 & 0.599 & 0.445 & \\
\hline & Generation & 5 & 1.377 & 0.262 & \\
\hline & Concentration & 6 & 0.633 & 0.703 & \\
\hline & $\mathrm{PxG}$ & 5 & 0.241 & 0.941 & \\
\hline & $\mathrm{PxC}$ & 6 & 0.843 & 0.547 & \\
\hline & $\mathrm{GxC}$ & 30 & 0.810 & 0.715 & \\
\hline & Residuals & 29 & & & \\
\hline \multirow[t]{8}{*}{ Fecundity } & Population & 1 & 5.335 & 0.021 & $*$ \\
\hline & Generation & 4 & 80.870 & $<0.001$ & $* * *$ \\
\hline & Concentration & 6 & 231.200 & $<0.001$ & $* * *$ \\
\hline & $P x G$ & 4 & 1.409 & 0.230 & \\
\hline & $\mathrm{PxC}$ & 6 & 0.315 & 0.929 & \\
\hline & $\mathrm{GxC}$ & 23 & 3.192 & $<0.001$ & $* * *$ \\
\hline & $\mathrm{PxGxC}$ & 22 & 0.754 & 0.782 & \\
\hline & Residuals & 462 & & & \\
\hline
\end{tabular}




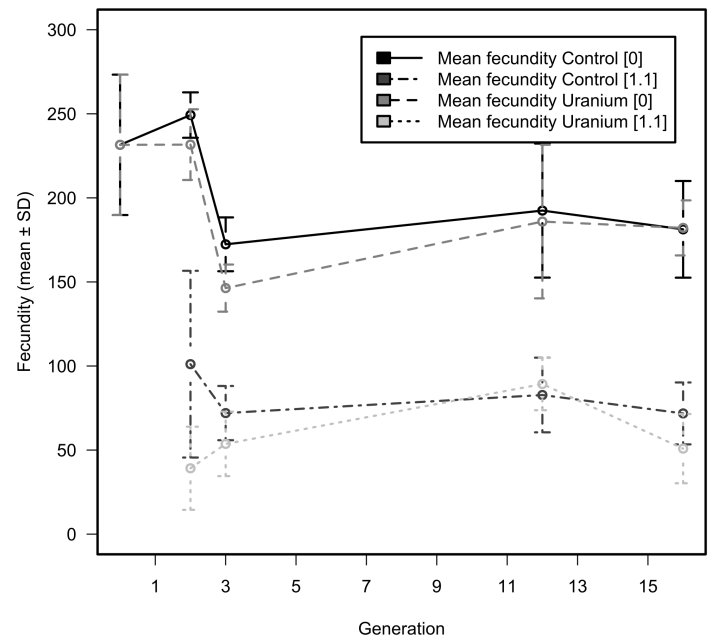

Figure 5: Mean fecundity ( \pm Standard Deviation) for individuals issued from MGC (Control population) and MGU (Uranium population) exposed to control conditions or $1.1 \mathrm{mM} \mathrm{U}$, as a function of the generation. Mean fecundity Control [0] represents fecundity for MGC exposed to control conditions, Mean fecundity Control [1.1] represents fecundity for MGC exposed to $1.1 \mathrm{mM} \mathrm{U}$, Mean fecundity Uranium [0] represents fecundity for MGU exposed to control conditions, and Mean fecundity Uranium [1.1] represents fecundity for MGU exposed to $1.1 \mathrm{mM} \mathrm{U}$.

MGU population and toxicity test at $1.1 \mathrm{mM} \mathrm{U}$ ) maximal length and fecundity were smaller than in control conditions (i.e. MGC population and toxicity test at $0 \mathrm{mM} \mathrm{U}$ ) by over $20 \%$ and $60 \%$ whatever the generation. For both populations and both males and hermaphrodites, the third Gompertz parameters $(a)$ were not impacted by uranium concentration (Anova Table 1).

Statistical analysis in Table 1 show that growth parameters $\left(L_{0}, L_{i n f}, a\right)$ did not differ between the two populations (MGC and MGU). In contrast, fecundity was clearly decreased in MGU population compared to MGC population (Anova Table 1, Fig. 5, and S3).

\subsection{Dose response relationship}

Our data showed that dose-responses for $L_{\text {inf }}$ and fecundity hardly varied whatever the population throughout the generations for hermaphrodite individuals (Table 2). Dose-responses for $L_{\text {inf }}$ for male individuals were irrelevant due to a lack of power at some toxicity test concentrations.

\section{Discussion}

In this study, the effects of uranium on growth, reproduction, survival, and evolution of dose-responses of individuals from two populations (control and exposed) of $C$. elegans were assessed.

In our experiment, we found at all generations ef-
Table 2: $\mathrm{EC}_{50}$ values relative to estimated maximal length $\left(L_{i n f}\right)$ and fecundity, as a function of generation and population. $\mathrm{EC}_{50}$ was calculated based on the regression of the dose-response curve relating endpoint value to the concentration, fitted with a logistic model. Estimates of the $\mathrm{EC}_{50}$, standard error (SE), and the lower and upper bounds of the $95 \%$ confidence interval are presented for each generation (G).

\begin{tabular}{lrrrrr}
\hline Observed traits & $\mathrm{G}$ & $\mathrm{EC}_{50}$ & $\mathrm{SE}$ & Lower & Upper \\
\hline$L_{\text {inf }}$ & 0 & 1.21 & 0.01 & 1.18 & 1.25 \\
Hermaphrodite & 3 & 1.36 & 0.05 & 1.25 & 1.47 \\
Control Population & 2 & 1.36 & 0.07 & 1.22 & 1.51 \\
& 6 & 1.14 & 0.03 & 1.08 & 1.20 \\
& 12 & 1.52 & 0.11 & 1.29 & 1.74 \\
& 16 & 1.26 & 0.03 & 1.20 & 1.32 \\
$L_{\text {inf }}$ & 0 & 1.22 & 0.03 & 1.16 & 1.27 \\
Hermaphrodite & 3 & 1.28 & 0.15 & 0.96 & 1.60 \\
Uranium Population & 2 & 1.38 & 0.10 & 1.16 & 1.59 \\
& 6 & 1.25 & 0.07 & 1.10 & 1.39 \\
& 12 & 1.39 & 0.11 & 1.16 & 1.63 \\
& 16 & 1.32 & 0.08 & 1.15 & 1.50 \\
\hline Fecundity & 0 & 0.98 & 0.02 & 0.93 & 1.03 \\
Control Population & 2 & 1.06 & 0.03 & 0.99 & 1.12 \\
& 3 & 1.05 & 0.05 & 0.96 & 1.15 \\
& 12 & 1.08 & 0.02 & 1.02 & 1.13 \\
Fecundity & 16 & 1.06 & 0.04 & 0.98 & 1.14 \\
Uranium Population & 0 & 0.98 & 0.02 & 0.93 & 1.03 \\
& 2 & 0.84 & 0.10 & 0.65 & 1.03 \\
& 3 & 1.05 & 0.04 & 0.97 & 1.13 \\
& 12 & 1.07 & 0.07 & 0.93 & 1.22 \\
& 16 & 0.97 & 0.03 & 0.90 & 1.04 \\
\hline
\end{tabular}


fects of uranium on maximal length and fecundity. The NOEC for growth of hermaphrodites and male was $0.9 \mathrm{mM} \mathrm{U}$. The NOEC for reproduction was $0.5 \mathrm{mM}$ U. Muscatello and Liber (2009) found effects on Chironomus tentans growth at concentrations above $157 \mu \mathrm{g} \mathrm{L}^{-1}$ and a NOEC of $39 \mu \mathrm{g} \mathrm{\textrm {L } ^ { - 1 }}(\tilde{0} .6 \mu \mathrm{M} \mathrm{U}$ and $\tilde{0} .1 \mu \mathrm{M} U$ ), but no effect on reproduction for exposure concentrations up to $835 \mu \mathrm{g} \mathrm{L}^{-1}(\tilde{3} .5 \mu \mathrm{M} \mathrm{U})$. Moreover, they showed a similar trend in growth reduction for exposed organisms and for unexposed organisms originated from adult males and females exposed to uranium during their immature life stages. Beaudouin et al. (2012) showed effects of uranium on both growth and reproduction of Chironomus riparius and also showed that exposure to uranium during eight generations led to a phenotypic selection via a differential survival characterized by longer time to emergence and smaller larval maximal size. They estimated a longterm No Effect Concentration (NEC) of $28.3 \mu \mathrm{g} \mathrm{g}^{-1}$ dry weight of sediment. There are only a few studies on the consequences of exposure to uranium during many successive generations although the uranium half-life can reach up to $4.5 \times 10^{9}$ years $\left({ }^{238} \mathrm{U}\right)$. Moreover, according to Klerks and Levinton (1989), a differential survival may appear in contaminated environments as least sensitive individuals may survive better. This may induce adaptation to the stressful environment. Such adaptation of individuals to a specific environment may lead to a decrease of the population fitness in a new environment or in an environment without the stressor (Jansen et al., 2011a,b; Lenormand et al., 1999; Salice et al., 2010; Ward and Robinson, 2005).

We did not observe any adaptation on growth as control and exposed populations were similar on each trait relative to growth. In contrast, we observed differentiations on reproduction traits. Indeed, a permanent decrease of fecundity appeared in the uranium population (MGU) compared to control population (MGC). This impact on reproductive traits may lead to adverse effects on the whole population. Indeed, Forbes and Calow (2002) demonstrated that effects on reproduction traits are significantly correlated with changes in the population growth rate - which is a robust endpoint for assessing ecological risks of pollutants (Billoir et al., 2007; Forbes and Calow, 1999). Although common gardens (i.e. individuals from uranium population replaced in control conditions) were performed for each studied generation, we did not show any significant results. This may be explained by the fact that experimental design did not allow us to perform common gardens for more than one generation. Indeed, observed effects should have been mitigated by within-individual (Scheiner, 1993) or cross-generation (i.e. maternal effects (Räsänen and Kruuk, 2007)) effects. In our study, as in Beaudouin et al. (2012), we showed an adaptation to experimental conditions in both exposed and unexposed populations. Indeed, an increase in maximal length and a decrease in fecundity were observed in both populations. This may be a direct consequence of differences between culture con- ditions and experimental conditions. We could explain these significant changes in both populations by experimental conditions. Indeed, during the experimentation, individuals were observed daily under a stereomicroscope near a flame as described in Stiernagle (2006) to ensure sterility and avoid contamination of plates. This process may have exposed individuals to a temperature of more than $20^{\circ} \mathrm{C}$ for several minutes each day. According to Byerly et al. (1976), C. elegans strain N2 individuals submitted to a temperature of $25^{\circ} \mathrm{C}$ grow faster, present a higher length at each stage and a lower fecundity than individuals cultured at $20^{\circ} \mathrm{C}$.

We noted that the third parameter of the Gompertz growth model $(a)$, which is related to the growth rate, did not depend on the exposure concentration, contrary to maximal length or fecundity. In accordance with available energy-based models analysing growth and reproduction data, such observation would indicate an effect on food assimilation or on maintenance over-cost (Billoir et al., 2008a,b). This would be consistent with other experimental and modelling studies which have also tackled the identification of the mode of action of uranium. Augustine et al. (2012) showed that the mode of action on zebrafish could be either a decrease of food assimilation or an increase of maintenance energetic costs. They also reported a complementary study showing a loss of gut wall architecture, presence of large necrotic zones and an overall decrease in gut bacteria, in accordance with an effect on assimilation. In a similar way, Massarin et al. (2011) analysed uranium toxicity data on D. magna showing a likely effect on assimilation based both on modelling of the growth and reproduction responses and histological analysis of uranium induced damage to the gut wall. The same kind of histological effects was observed on the earthworm Eisenia fetida exposed to soil contaminated with uranium (Giovanetti et al., 2010). In our study we can hypothesize that increase of uranium concentration causes both damages to the gut wall and decrease of food availability. Indeed, according to Boyd et al. (2003) and Yeates (1998) C. elegans cannot ingest microbeads with a diameter of $5 \mu \mathrm{m}$ or more and our observations suggest that some bacterial aggregates may appear at high uranium concentrations. These observations are coherent with studies assessing interactions between uranium and Gram-negative bacteria cell wall such as E. coli (Barkleit et al., 2008; Lutke et al., 2012). According to these studies, such interactions are mainly due to carboxylate and phosphate groups expressed on the outer membrane of lipopolysaccharide of Gram-negative bacteria.

As the range of uranium concentration used in our study was chosen to be sublethal, we did not observe any effect of uranium on survival of $C$. elegans. To our knowledge, only two studies have assessed the effect of uranium on $C$. elegans survival. In these studies, the wild-type N2 $C$. elegans strain was used and survival was affected from $1.34 \mathrm{mM} \mathrm{U}$ and the lethal concentration for $50 \%$ of individuals $\left(\mathrm{LC}_{50}\right)$ at 48 hours was 
$1.71 \mathrm{mM} \mathrm{U}(95 \% \mathrm{CI}=1.62-1.80)$ in NGM (Dutilleul et al., 2013). In a 30 min water medium exposure, the $\mathrm{LC}_{50}$ at 24 hours was found to be $66.9 \mu \mathrm{M} \mathrm{U} \pm 30.9$ (Jiang et al., 2009). These differences of responses as a function of the exposure media composition are known whatever the studied organism. Indeed Misson et al. (2009) showed that uranium effects on Arabidopsis thaliana greatly differ with or without the presence of inorganic-phosphate and Zeman et al. (2008) showed that uranium toxicity on D. magna varies with $\mathrm{pH}$ variations.

\section{Conclusion}

Uranium appears to exert adverse effects on $C$. elegans growth and reproduction. In our multi-generations study, we found no adaptation regarding growth parameters. In contrast, a permanent decrease of fecundity appeared in the population exposed to uranium for several generations. Our results confirm the need of multi-generational studies for assessment of environmental risks of pollutant on long term population dynamics.

Acknowledgements We are especially grateful to Catherine Lecomte for discussions and suggestion on this project, Audrey Sternalski for discussion and punctual help, Virginie Camilleri for technical assistance with the ICP-AES measurements, and Cleo Tebby for linguistic corrections, statistical validation and discussion. We also thank Henrique Teotónio for providing us with his base population and for comments. The authors are also grateful to two anonymous reviewers for their valuable comments and suggestions on the manuscript. This work was part of the Envirhom-Eco research program supported by the french Institute for Radioprotection and Nuclear Safety (IRSN) and the 190 DRC-08-02 program supported by the french Ministry of Ecology.

Ethical standard and conflict of interest The authors declare that they have no conflict of interest and that the experiments comply with the current law of the country in which they were performed.

\section{References}

Altun, Z. and Hall, D. (2009). Introduction. In WormAtlas. WormAtlas, http://www.wormatlas.org.

Araiz, C., Château, M.-T., Descamps, S., and Galas, S. (2008). Quantitative genomics in Caenorhabditis elegans: Identification strategies for new human therapeutic targets and molecular mechanisms. IRBM, 29(5):289-296.

Augustine, S., Gagnaire, B., Adam-Guillermin, C., and Kooijman, S. A. L. M. (2012). Effects of uranium on the metabolism of zebrafish, Danio rerio. Aquatic Toxicology, 118:9-26.

Barkleit, A., Moll, H., and Bernhard, G. (2008). Interaction of uranium(VI) with lipopolysaccharide. Dalton Transactions, (21):2879-2886.
Beaudouin, R., Dias, V., Bonzom, J., and Péry, A. (2012). Individual-based model of Chironomus riparius population dynamics over several generations to explore adaptation following exposure to uraniumspiked sediments. Ecotoxicology, 21(4):1225-1239. 10.1007/s10646-012-0877-4.

Bickham, J. (2011). The four cornerstones of Evolutionary Toxicology. Ecotoxicology, 20:497-502.

Billoir, E., Delignette-Muller, M.-L., Péry, A. R., Geffard, O., and Charles, S. (2008a). Statistical cautions when estimating DEBtox parameters. Journal of Theoretical Biology, 254(1):55-64.

Billoir, E., Delignette-Muller, M. L., Péry, A. R. R., and Charles, S. (2008b). A Bayesian Approach to Analyzing Ecotoxicological Data. Environmental Science \& Technology, 42(23):8978-8984.

Billoir, E., Péry, A. R., and Charles, S. (2007). Integrating the lethal and sublethal effects of toxic compounds into the population dynamics of Daphnia magna: A combination of the DEBtox and matrix population models. Ecological Modelling, 203(34):204-214.

Boyd, W., Cole, R., Anderson, G., and Williams, P. (2003). The effects of metals and food availability on the behavior of Caenorhabditis elegans. Environmental Toxicology and Chemistry, 22(12):3049-3055.

Brenner, S. (1974). Genetics of Caenorhabditis elegans. Genetics, 77(1):71-94.

Byerly, L., Cassada, R. C., and Russell, R. L. (1976). The life cycle of the nematode Caenorhabditis elegans : I. Wild-type growth and reproduction. Developmental Biology, 51(1):23-33.

Coutellec, M.-A. and Barata, C. (2011). An introduction to evolutionary processes in ecotoxicology. Ecotoxicology, 20(3):493-496.

Coutellec, M.-A., Collinet, M., and Caquet, T. (2011). Parental exposure to pesticides and progeny reaction norm to a biotic stress gradient in the freshwater snail Lymnaea stagnalis. Ecotoxicology, 20:524-534.

Dutilleul, M., Lemaire, L., Lecomte, C., Réale, D., Galas, S., and Bonzom, J.-M. (2013). Rapid phenotypic changes in Caenorhabditis elegans under uranium exposure. Manuscript submitted for publication.

Forbes, V. and Calow, P. (2002). Population growth rate as a basis for ecological risk assessment of toxic chemicals. Philisophical Transactions of The Royal Society of London Series B-Biological Sciences, 357(1425):1299-1306.

Forbes, V. E. and Calow, P. (1999). Is the per capita rate of increase a good measure of population-level effects in ecotoxicology? Environmental Toxicology and Chemistry, 18(7):1544-1556. 
Gagliano, M. and McCormick, M. I. (2007). Maternal condition influences phenotypic selection on offspring. Journal of Animal Ecology, 76(1):174-182.

Giovanetti, A., Fesenko, S., Cozzella, M. L., Asencio, L. D., and Sansone, U. (2010). Bioaccumulation and biological effects in the earthworm Eisenia fetida exposed to natural and depleted uranium. Journal of Environmental Radioactivity, 101(6):509 - 516.

Harada, H., Kurauchi, M., Hayashi, R., and Eki, T. (2007). Shortened lifespan of nematode Caenorhabditis elegans after prolonged exposure to heavy metals and detergents. Ecotoxicology and Environmental Safety, 66:378-383.

Hendry, A. P. and Gonzalez, A. (2008). Whither adaptation? Biology 8 Philosophy, 23:673-699.

Hoffmann, A. A. and Merilä, J. (1999). Heritable variation and evolution under favourable and unfavourable conditions. Trends in Ecology 85 Evolution, 14(3):96 - 101.

Jansen, M., Coors, A., Stoks, R., and de Meester, L. (2011a). Evolutionary ecotoxicology of pesticide resistance: a case study in Daphnia. Ecotoxicology, 20:543-551.

Jansen, M., Stoks, R., Coors, A., van Doorslaer, W., and de Meester, L. (2011b). Collateral damage: rapid exposure-induced evolution of pesticide resistance leads to increased susceptibility to parasites. Evolution, 65(9):2681-2691.

Jiang, G. C. T., Hughes, S., Sturzenbaum, S. R., Evje, L., Syversen, T., and Aschner, M. (2009). Caenorhabditis elegans Metallothioneins Protect against Toxicity Induced by Depleted Uranium. Toxicological Sciences, 111(2):345-354.

Klerks, P. and Levinton, J. (1989). Rapid Evolution of Metal Resistance in a Benthic Oligochaete Inhabiting a Metal-polluted Site. Biological Bulletin, 176(2):135-141.

Lenormand, T., Bourguet, D., Guillemaud, T., and Raymond, M. (1999). Tracking the evolution of insecticide resistance in the mosquito Culex pipiens. Nature, 400(6747):861-864.

Lopes, P., Sucena, E., Santos, M., and Magalhães, S. (2008). Rapid experimental evolution of pesticide resistance in $C$. elegans entails no costs and affects the mating system. PLoS ONE, 3(11).

Lutke, L., Moll, H., and Bernhard, G. (2012). Insights into the uranium(vi) speciation with Pseudomonas fluorescens on a molecular level. Dalton Transactions, 41:13370-13378.

Massarin, S., Beaudouin, R., Zeman, F., Floriani, M., Gilbin, R., Alonzo, F., and Pery, A. R. R. (2011).
Biology-Based Modeling To Analyze Uranium Toxicity Data on Daphnia magna in a Multigeneration Study. Environmental Science \& Technology, 45(9):4151-4158.

Maupas, E. (1900). Modes et formes de reproduction des nématodes. Archives de Zoologie Expérimentale et Générale, 8:463-624.

Misson, J., Henner, P., Morello, M., Floriani, M., Wu, T.-D., Guerquin-Kern, J.-L., and Février, L. (2009). Use of phosphate to avoid uranium toxicity in Arabidopsis thaliana leads to alterations of morphological and physiological responses regulated by phosphate availability. Environmental and Experimental Botany, 67(2):353 - 362.

Mkandawire, M., Vogel, K., Taubert, B., and Dudel, E. G. (2007). Phosphate regulates uranium(VI) toxicity to Lemna gibba L. G3. Environmental Toxicology, 22(1):9-16.

Morran, L. T., Cappy, B. J., Anderson, J. L., and Phillips, P. C. (2009a). Sexual partners for the stressed: facultative outcrossing in the selffertilizing nematode Caenorhabditis elegans. Evolution, 63(6):1473-1482.

Morran, L. T., Parmenter, M. D., and Phillips, P. C. (2009b). Mutation load and rapid adaptation favour outcrossing over self-fertilization. Nature, 462(7271):350-352.

Mousseau, T. A. and Fox, C. W. (1998). The adaptive significance of maternal effects. Trends in Ecology 8 Evolution, 13(10):403 - 407.

Muscatello, J. and Liber, K. (2009). Accumulation and Chronic Toxicity of Uranium Over Different Life Stages of the Aquatic Invertebrate Chironomus tentans. Archives of Environmental Contamination and Toxicology, 57:531-539.

Muyssen, B. T. and Janssen, C. R. (2004). Multigeneration cadmium acclimation and tolerance in Daphnia magna Straus. Environmental Pollution, 130(3):309 - 316 .

R Core Team (2012). R: A Language and Environment for Statistical Computing. R Foundation for Statistical Computing, Vienna, Austria. ISBN 3-900051$07-0$.

Rasband, W. (2012). ImageJ, U. S. National Institutes of Health, Bethesda, Maryland, USA. online.

Ribera, D., Labrot, F., Tisnerat, G., and Narbonne, J.F. (1996). Uranium in the environment: occurrence, transfer, and biological effects. Reviews in Environmental Contamination and Toxicology, 146:53-89.

Ritz, C. and Streibig, J. C. (2005). Bioassay Analysis using R. Journal of Statistical Software, 12. 
Räsänen, K. and Kruuk, L. E. B. (2007). Maternal effects and evolution at ecological time-scales. Functional Ecology, 21(3):408-421.

Salice, C. J., Anderson, T. A., and Roesijadi, G. (2010). Adaptive responses and latent costs of multigeneration cadmium exposure in parasite resistant and susceptible strains of a freshwater snail. Ecotoxicology, 19:1466-1475.

Scheiner, S. (1993). Genetics and Evolution of Phenotypic Plasticity. Annual review of ecology and systematics, 24:35-68.

Shen, L., Xiao, J., Ye, H., and Wang, D. (2009). Toxicity evaluation in nematode Caenorhabditis elegans after chronic metal exposure. Environmental Toxicology and Pharmacology, 28(1):125 - 132.

Sheppard, S. C., Sheppard, M. I., Gallerand, M.-O., and Sanipelli, B. (2005). Derivation of ecotoxicity thresholds for uranium. Journal of Environmental Radioactivity, 79(1):55 - 83.

Sochová, I., Hofman, J., and Holoubek, I. (2007). Effects of seven organic pollutants on soil nematode Caenorhabditis elegans. Environment International, 33(6):798 - 804 .

Stiernagle, T. (2006). Maintenance of C. elegans. In Wormbook, pages $1-11$. The $C$. elegans Research Community, WormBook.

Sutphin, G. L. and Kaeberlein, M. (2009). Measuring Caenorhabditis elegans Life Span on Solid Media. JoVE, 27.

Swain, S., Keusekotten, K., Baumeister, R., and Sturzenbaum, S. (2004). C. elegans metallothioneins: New insights into the phenotypic effects of cadmium toxicosis. Journal of Molecular Biology, 341(4):951-959.

Swain, S., Wren, J., Stürzenbaum, S., Kille, P., Morgan, A., Jager, T., Jonker, M., Hankard, P., Svendsen, C., Owen, J., Hedley, B., Blaxter, M., and Spurgeon, D. (2010). Linking toxicant physiological mode of action with induced gene expression changes in Caenorhabditis elegans. BMC Systems Biology, 4:-.

Teotónio, H., Carvalho, S., Manoel, D., Roque, M., and Chelo, I. (2012). Evolution of outcrossing in experimental populations of Caenorhabditis elegans. PLoS ONE, 7(4):1-13.

UNSCEAR (2000). Report Vol 1. Sources and effects of ionizing radiation. Technical report, United Nations, New-York.

Ward, T. J. and Robinson, W. E. (2005). Evolution of cadmium resistance in Daphnia magna. Environmental Toxicology and Chemistry, 24(9):2341-2349.
Yeates, G. (1998). Feeding in free-living soil nematodes: A functional approach. In Perry, R. and Wright, D., editors, The physiology and biochemistry of free-living and plant-parasitic nematodes., pages 245-269. CAB INTERNATIONAL, New York, NY, USA.

Zeman, F. A., Gilbin, R., Alonzo, F., LecomtePradines, C., Garnier-Laplace, J., and Aliaume, C. (2008). Effects of waterborne uranium on survival, growth, reproduction and physiological processes of the freshwater cladoceran Daphnia magna. Aquatic Toxicology, 86(3):370 - 378 . 

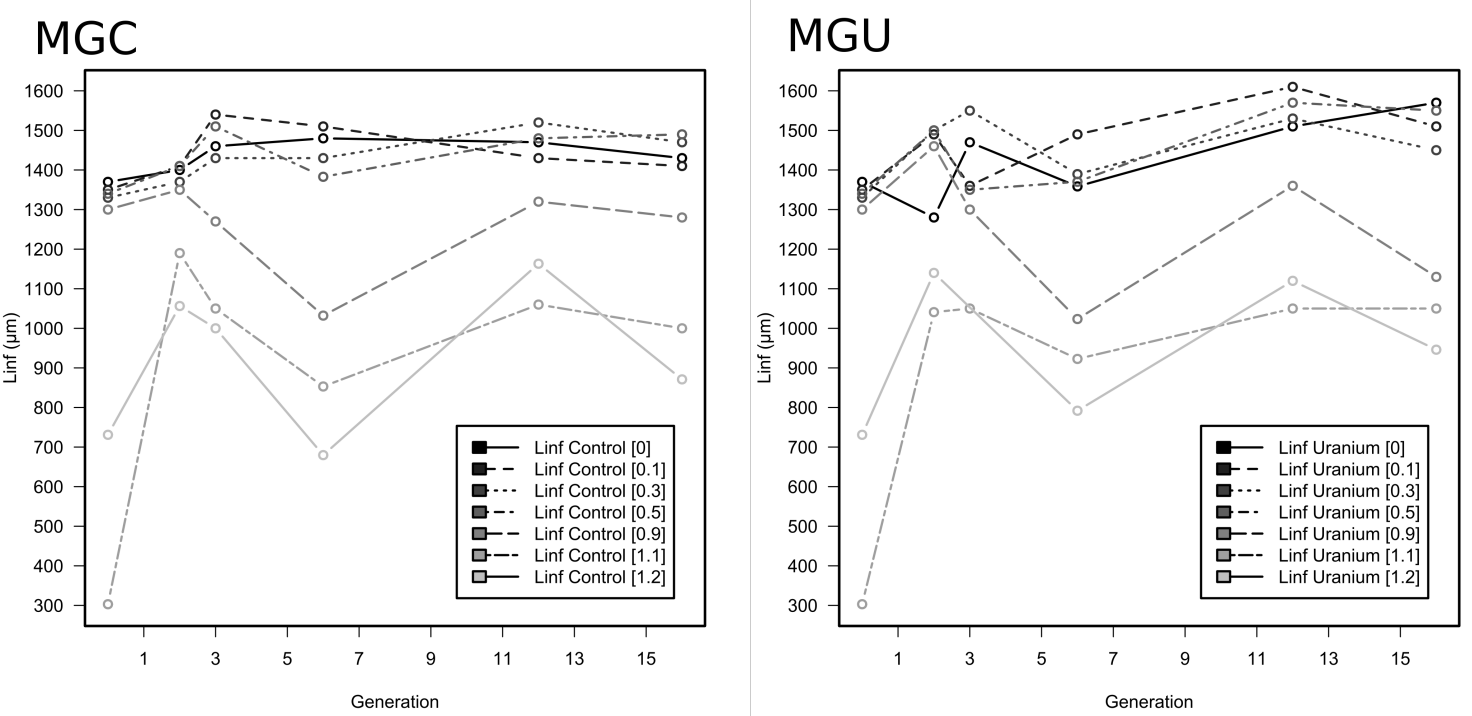

Figure S1: Maximal length $\left(L_{i n f}\right)$ for hermaphrodite individuals $(\mu \mathrm{m})$ as a function of the generation for MGC (Control population) and MGU (Uranium population) exposed to $0 \mathrm{mM} \mathrm{U}, 0.1 \mathrm{mM} \mathrm{U}, 0.3 \mathrm{mM} \mathrm{U}, 0.5 \mathrm{mM} \mathrm{U}, 0.9 \mathrm{mM} \mathrm{U}, 1.1 \mathrm{mM}$ U, and $1.2 \mathrm{mM} \mathrm{U}$. Each point represents the $L_{\text {inf }}$ value of the model (Eq. (1)) fitted using all replicate for each treatment
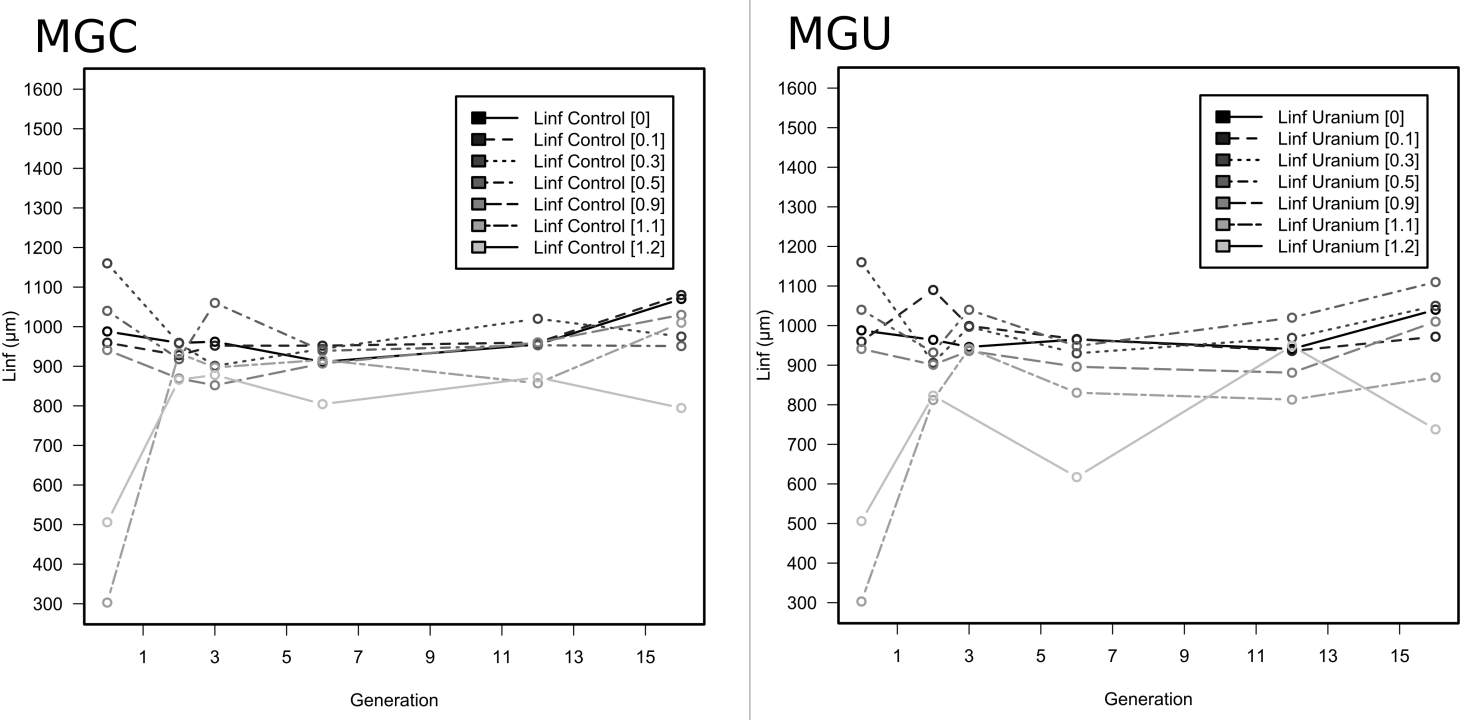

Figure S2: Maximal length (Linf) for male individuals $(\mu \mathrm{m})$ as a function of the generation for MGC (Control population) and MGU (Uranium population) exposed to $0 \mathrm{mM} \mathrm{U}, 0.1 \mathrm{mM} \mathrm{U}, 0.3 \mathrm{mM} \mathrm{U}, 0.5 \mathrm{mM} \mathrm{U}, 0.9 \mathrm{mM} \mathrm{U}, 1.1 \mathrm{mM} \mathrm{U}$, and $1.2 \mathrm{mM}$ U. Each point represents the $L_{i n f}$ value of the model (Eq. (1)) fitted using all replicate for each treatment 

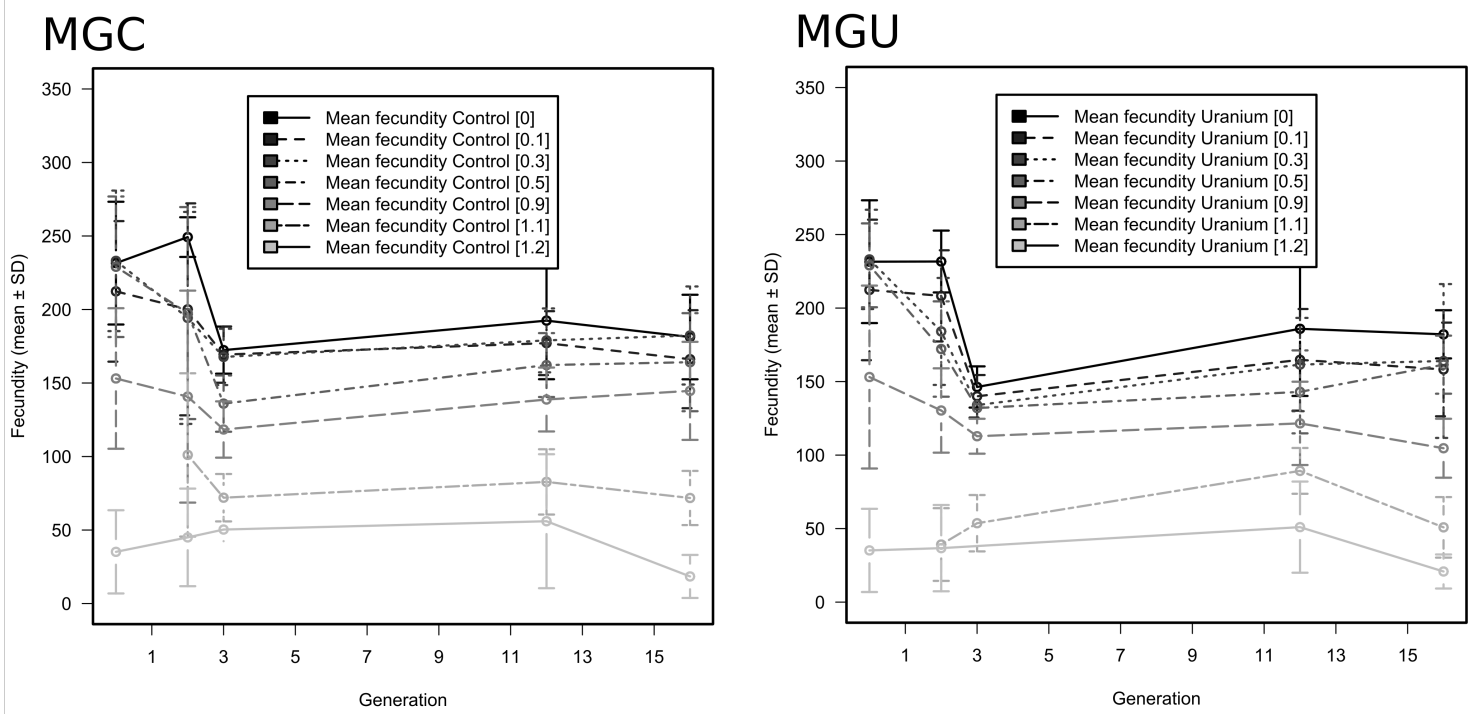

Figure S3: Mean fecundity ( \pm Standard Deviation) as a function of the generation for MGC (Control population) and MGU (Uranium population) exposed to $0 \mathrm{mM} \mathrm{U}, 0.1 \mathrm{mM} \mathrm{U}, 0.3 \mathrm{mM} \mathrm{U}, 0.5 \mathrm{mM} \mathrm{U}, 0.9 \mathrm{mM} \mathrm{U}, 1.1 \mathrm{mM} \mathrm{U}$, and $1.2 \mathrm{mM}$ U. 